\title{
BONE MORPHOGENETIC PROTEINS AS REGULATORS OF NEURAL TUBE DEVELOPMENT
}

\author{
Aimar Namm ${ }^{1,2}$, Andres Arend ${ }^{1}$, Marina Aunapuu ${ }^{1,2}$ \\ ${ }^{1}$ Department of Anatomy, University of Tartu, Tartu, Estonia \\ ${ }^{2}$ Department of Veterinary Medicine, Estonian University of Life Sciences, \\ Tartu, Estonia
}

\section{INTRODUCTION}

Bone morphogenetic proteins (BMP-s) belong to the transforming growth factor (TGF) $\beta$ superfamily that mediates a multitude of developmental processes in various tissues. In recent years the roles of BMP-s in embryonic development and cellular functions have been extensively studied. The important roles of BMP signalling in the development of nervous system, heart, cartilage and bone have been demonstrated by studies of transgenic and knockout mice as well as of animals and humans with naturally occurring mutations in BMPs and related genes [5]. The central nervous system (CNS) is highly regionalized along both its anterposterior and dorsoventral axes [27]. Anterioposterior regionalization of the CNS is clearly evident from the localization of cerebral cortex at the anterior end, spatially and functionally distinct areas that arise within forebrain, midbrain and hindbrain, and spinal cord at the posterior end. Similary, different neurons and neural structures originate at specific dorsoventral positions of the neural tube. Within the ectoderm, BMP activity has been shown to inhibit neural development, promote epidermal differentiation and influence the specification of dorsal neurons and neural crest [1].

In this review we highlight the temporal and spatial influence of BMP signalling from the earliest step of neural induction to neural tube patterning when the forebrain, midbrain, hindbrain, and the spinal cord at the posterior end are formed. 


\section{GENERAL FUNCTIONS AND CLASSIFICATION OF BMP-s}

Bone morphogenetic proteins, now widely known for their involvement in many biological processes, were first examined for their ability to induce cartilage and bone formation, and this was the reason for assigning this group of proteins their names. BMP-s were first described by Dr. Marshall Urist in 1965 [39]. Four proteins were initially identified, and one of them, BMP-1 is a metalloproteinase [23]. The other three (BMP-2, -3 and -4 ) are members of the transforming growth factor $\beta$ (TGF $\beta$ ) superfamily and they mediate a multitude of developmental processes in various tissues. Subsequently, molecular cloning studies have identified more than 20 members of the BMP subgroup in the TGF $\beta$ family, from various species [23]. As shown in Table 1, several BMP-s possess monikers owing to the diversity of their effects observed in multiple species and tissues [34]. Because BMP-s have been isolated from different species, several of the BMP-s have alternate names that are often used interchangeably [28]. For instance, BMP-7 is OP-1, BMP-11 is GDF-8 and etc. Although it is not known whether all of the members of this subgroup are involved in bone differentiation, they control a wide range of biological processes in various cell types. This class of proteins has been shown to have roles in cellular lineage commitment, differentiation, proliferation, patterning, morphogenesis, cellular maintenance and apoptosis [34]. There are also increasing evidence that secreted signalling molecules of the BMP superfamily play versatile roles in many aspects of embryonic development, including neurogenesis [14]. 
Table 1. Functions of bone mophogenetic proteins

\begin{tabular}{|c|c|}
\hline BMP & Functions \\
\hline BMP-1 & $\begin{array}{l}\text { Induces bone and cartilage. Involved in dorsoventral } \\
\text { patterning. }\end{array}$ \\
\hline BMP-2 & $\begin{array}{l}\text { Induces osteoblast differentiation and osteogenesis. } \\
\text { Involved in cardiac cell differentiation, epithelial to } \\
\text { mesenchymal transition, dorsoventral patterning and } \\
\text { craniofacial development. }\end{array}$ \\
\hline $\begin{array}{l}\text { BMP-3 (osteo- } \\
\text { genin/GDF-10) }\end{array}$ & $\begin{array}{l}\text { It is an osteogenesis inhibitor, it negatively regulates } \\
\text { bone density. Involved in dorsoventral patterning. }\end{array}$ \\
\hline BMP-4 & $\begin{array}{l}\text { Involved in bone mineralisation, muscle development, } \\
\text { formation of teeth, limbs, lungs and eyes. Also involved } \\
\text { in dorsoventral patterning and craniofacial development. }\end{array}$ \\
\hline BMP-5 & $\begin{array}{l}\text { Induces bone and cartilage development. Involved in } \\
\text { formation of liver, lung and optic nerve. }\end{array}$ \\
\hline BMP-6 & $\begin{array}{l}\text { Induces osteogenic markers in mesenchymal stem cells. } \\
\text { Involved in joint integrity. }\end{array}$ \\
\hline BMP-7 (OP-1) & $\begin{array}{l}\text { Involved in the transformation of mesenchymal cells into } \\
\text { bone and cartilage. Also involved in kidney, bladder, } \\
\text { brain and and craniofacial development. }\end{array}$ \\
\hline $\begin{array}{l}\text { BMP-8 } \\
(\mathrm{OP}-2 / 3)\end{array}$ & $\begin{array}{l}\text { Induces bone and cartilage development. Involved in } \\
\text { craniofacial development. }\end{array}$ \\
\hline BMP-9 & $\begin{array}{l}\text { Involved in chondrogenesis, hepatogenesis and nervous } \\
\text { system development. }\end{array}$ \\
\hline BMP-10 & Involved in the trabeculation of embryonic heart. \\
\hline $\begin{array}{l}\text { BMP-11 } \\
\text { (GDF-8) }\end{array}$ & $\begin{array}{l}\text { Involved in the mesodermal patterning and nervous } \\
\text { system development. }\end{array}$ \\
\hline $\begin{array}{l}\text { BMP-12 } \\
\text { (GDF- } \\
\text { 7/CDMP-3) }\end{array}$ & $\begin{array}{l}\text { Induces joint morphogenesis. Facilitates growth of } \\
\text { ligament. }\end{array}$ \\
\hline $\begin{array}{l}\text { BMP-13 } \\
\text { (GDF- } \\
\text { 6/CDMP-2) }\end{array}$ & $\begin{array}{l}\text { Induces joint morphogenesis. Facilitates growth of } \\
\text { ligament. }\end{array}$ \\
\hline BMP-14 & $\begin{array}{l}\text { Involved in chondrogenesis, limbs development and } \\
\text { fracture healing. Facilitates growth of tendon. }\end{array}$ \\
\hline BMP-15 & Involved in the oocyte and follicular development. \\
\hline
\end{tabular}




\section{BMP-s INFLUENCE THE PROCESS OF NEURULATION}

Neurulation is the process of forming the neural tube, which will become the brain and spinal cord [30]. The embryonic precursor of the neural tube is the neural plate, or neuroepithelium, a thickened region of ectoderm on the dorsal surface of the early embryo [9]. The neural plate is subsequently converted into the neural tube by a two-stage process. Primary neurulation gives rise to the neural tube that will later develop into the brain and most of the spinal cord. This process involves shaping and folding of the neuroepithelium, with formation of neural folds that undergo fusion in the midline to generate the neural tube and create two continuous epithelial layers: surface ectoderm on the outside and the inner neural tube [10]. Secondary neurulation leads to the formation of the neural tube in the caudal sacral and coccygeal regions [15]. In the neural tissue BMP signalling is essential for many steps of neural development. BMP-s act at different stages of neural development and in different regions of the CNS to regulate cell fate, proliferation and differentation. The first step is an early embryonic cell fate decision that determines whether cells will form neural or non-neural ectoderm [26]. The CNS initially develops from the dorsomedial region of the embryonic ectoderm, a process that requires the active repression of BMP signals. Although BMP activity must be inhibited to allow initial neural fate determination, it is clear that BMP signalling positively regulates CNS development at later stages of development [33]. Once the neural tissue is established, BMP signalling has a positive influence on the regulation of dorsal neural cell type formation [26].

\section{BMP SIGNALLING INHIBITION ACTIVATES NEURAL INDUCTION}

During neural induction the embryonic neural plate is specified and set aside from other parts of the ectoderm. Several recent studies have shown that BMP-s are expressed in the ectoderm surrounding the entire neural plate [4], domains where phosphorylated Smad-I is also detected, indicative of active BMP signalling [13]. A widespread molecular explanation is the "default model" of neural induction, which proposes that high BMP activity defines epidermis, while absence of BMP specifies the neural plate [32]. It has also been proposed that intermediate concentrations specify the border of the neural plate, including 
the region fated to give rise to placodes and neural crest [40]. BMP causes the inwards displacement of the border (narrowing the neural plate), while antagonists cause the reverse [32]. There is no doubt that the modulation of BMP activity (including the control of Smad I) is crucially important for neural development to occur normally [22]. BMP signalling apparently needs to be inhibited at least three times during early development to generate a normal neural plate [32]. The first inhibition takes place at very early stages of development, the second at the mid-/late gastrula stage and the third at the late gastrula/early neurula stage. These inhibitions establish the initial dorsoventral polarity of the embryo and also establish the differential competence of different ectodermal regions to respond to later signals. Chordin and noggin are probably the most important BMP antagonists in these developmental stages. These BMP activity repressions (in particular BMP-4, which acts as an epidermal inducer) led researchers to construct the "default model" of neural induction, which proposes that cells within the ectoderm have an autonomus tendency to differentiate into neural tissue [16]. These neural inducers induce only forebrain and midbrain types of tissues. Induction of caudal neural tube structures, hindbrain and spinal cord, depends on two other secreted proteins, Wnt-s and FGF-s. In addition, RA (retionic acid) appears to play a role in organizing the cranial-caudal axis $[38,40]$.

\section{BMP-s PROMOTE AND INFLUENCE NEURAL CREST CELLS}

The role of BMP signalling in neural crest induction is tightly linked to the induction of the neural plate [17]. After gastrulation, neural crest cells are specified at the border of the neural plate and the non-neural ectoderm. The periferial nervous system arises from neural crest and placodal cells derived from neural plate border cells. Neural crest cells, which contribute to a vast array of cell types are generated along the entire rostrocaudal neuroaxis where the neural plate border cells generate placodal but no neural crest cells [29]. The ability to segregate and migrate away from the neuroepithelium is one of the unique features of the developing neural crest, and for many years, the neural crest has been the preferred model to analyze the molecular basis of cell migration in normal and also pathological situations [35]. Induction of neural crest cells requires an interaction at the junctional border of the 
neural plate and surface ectoderm. Intermediate concentration of BMP-s is established at this boundary compared to neural plate cells that are exposed to very low levels of BMP-s and surface ectoderm cells that are exposed to very high levels. The proteins chordin, noggin and follistatin regulate these concentrations by acting as BMP inhibitors [17]. The intermediate concentration of BMP-s, together with Wnt proteins, induce Pax genes and other transcription factors that "specify" the neural plate border. We have a unique opportunity to examine a substantial number of human embryos at the stages of neural tube formation. Figure 1 shows intermediate expression of BMP-4 in neural crest cells during the development of the neural tube. It still remains unclear whether BMP and other proteins (Wnt, $\mathrm{SHH}$ ) signals act in parallel or have separate roles during the initial induction of neural crest cells [29].

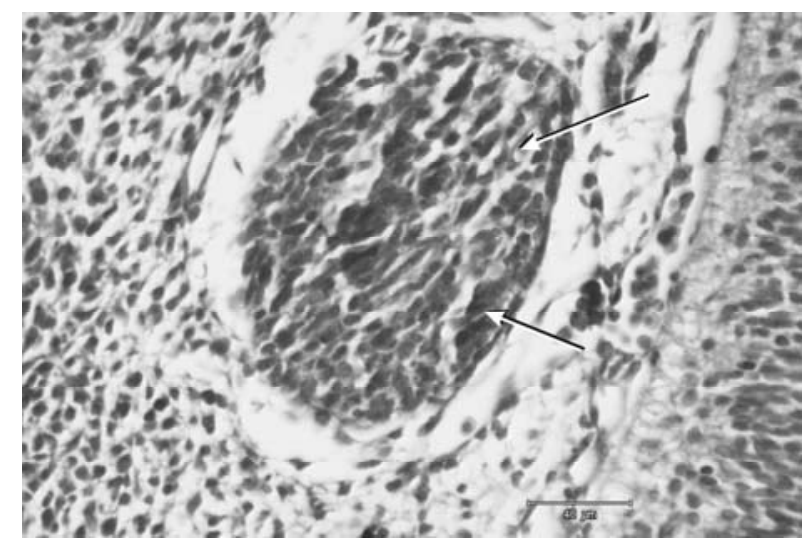

Figure 1. BMP-4 expression in the neural crest cells during the developement of the neural tube. Arrows indicate intesive immunostaining of neural crest cells (Carnegie stage 16).

\section{ROLE OF BMP-s IN DORSAL-VENTRAL PATTERNING OF THE NEURAL TUBE}

Members of the BMP family of signalling proteins are involved in embryonic dorsoventral patterning in both vertebrates and invertebrates [2]. A widely accepted model of dorsoventral patterning postulates that a morphogenetic BMP activity gradient patterns cell fates of all of the 
dorso-ventral axis. It has been suggested that members of the TGF $\beta$ superfamily, including several of the BMP-s, play a similar role in the dorsal neural tube [36]. The specification of dorsal neuronal cell fates appears to depend on a cascade of inductive signals initiated by cells of epidermal ectoderm that flank the neural plate and propagated by roof plate cells within the neural tube [24, 7]. BMP proteins have a prominent role in mediating these dorsalizing signals. Targeted mutations of BMP signalling components in the mouse also indicate a role for BMP signalling in dorsoventral patterning in mammals [37]. Our work with human embryos points to the considerable expression of BMP-2 and BMP-4 in the dorsal part of the developing neural tube (Figure 2). Thus, the results of BMP-2 and BMP-4 expression in the human developing neural tube are generally in concordance with the data obtained from animal studies supporting the idea that BMP-s are key regulators in the differentiation of the neural tissue, especially in the dorsal part of the neural tube. Additional signals, including members of the Wnt and FGF families, may also contribute to the proliferation and differentiation of dorsal neuronal cell types.

The level of BMP signalling may be modulated by a diverse group of proteins that emanate from the dorsal side of the embryo and inhibit BMP activity. Chordin, noggin and follistatin can all bind directly to BMP-s and overexpression studies have demonstrated that these proteins dorsalise embryos through the inhibition of BMP activity [11]. Unlike BMP-2 and BMP-4, noggin and chordin may diffuse within the embryo and so a gradient of BMP activity could be established through widespread production of BMP-s whose signalling activity is modulated by the activity of BMP antagonists diffusing from the dorsal side of the embryo [21] and thus a gradient of BMP-dependent positional information extending throughout the entire neural and non-neural ectoderm is formed [1]. Figure 3 demonstrates BMP-4 expression in the nonneural ectoderm during the development of the neural tube of human embryos. 


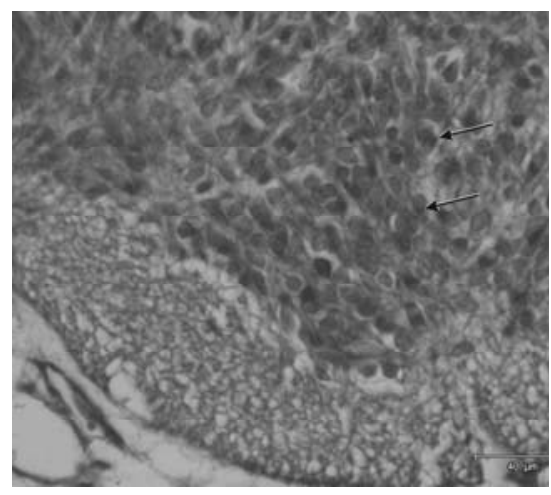

Figure 2. BMP-4 expression in the dorsal part of the developing neural tube (Carnegie stage 14).

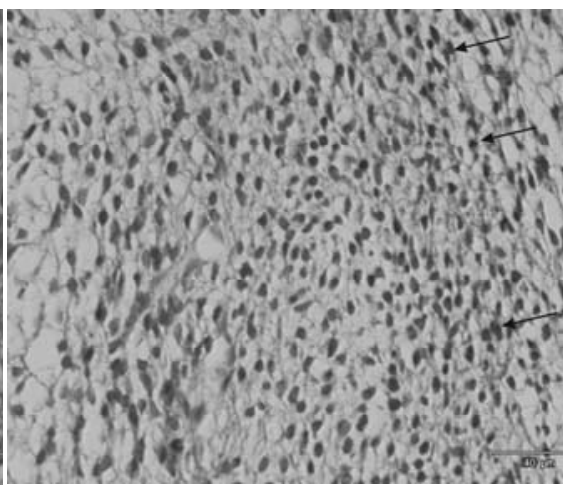

Figure 3. BMP-4 expression in the non-neural ectoderm during the development of the neural tube (Carnegie stage 18).

\section{BMP-s SIGNALLING AND ESTABLISHMENT OF THE SPINAL CORD}

After neural tube closure the most anterior end of the neural tube gives rise to the forebrain consisting of the telencephalon and the diencephalon, while the posterior regions form the midbrain, the hindbrain and the spinal cord [31]. As the caudal neural tube closes, roof plate progenitors differentiate into mature roof plate cells, which occupy the dorsal midline region. Roof plate cells act as a dorsal midline organizing center controlling numerous aspects of dorsal spinal cord development [8]. The first evidence for a role of roof plate in dorsal spinal cord patterning came from chick and mice studies [5, 6], and nowadays the dorsal patterning mechanisms are best described in the developing spinal cord. Several members of the BMP family are specially expressed in the roof plate during neural tube development at the dorsal interneuron formation in both mouse and chick. Expression of BMP-s also appeared in the roof plate of the developing spinal cord of human embryos (Figures 4, 5). In addition to the BMP-s expression of the roof plate, significant expression of BMP-s in non-neural ectoderm and neural crest cells was evident (Figure 4). 
The dorsoventral patterning is dictated by $\mathrm{SHH}$ emananting from ventral regions of the neural tube and BMP-s and Wnt-s originating from the dorsal position. In addition, the members of the FGF family have a specific role in the control of proliferation and patterning of neural progenitors [38]. Several lines of evidence indicate that BMP signalling contributes to the patterning of dorsoventral axis of the neural tube and is required for the correct specification of cell types in dorsal regions [41]. In addition, BMP-s antagonise SHH activity in the neural tube and influence the proliferation of neural progenitors. Importantly, the effects of BMP-s on cell proliferation in the neural tube may be mediated by Wnt signalling and conversely, Wnt signalling can transcriptionally be induced by BMP-s [18]. The molecular mechanism of this cross-inhibition remains to be elucidated. These findings have led researchers to propose that growth in the dorsal spinal cord is regulated by a balance between Wnt and BMP signalling.

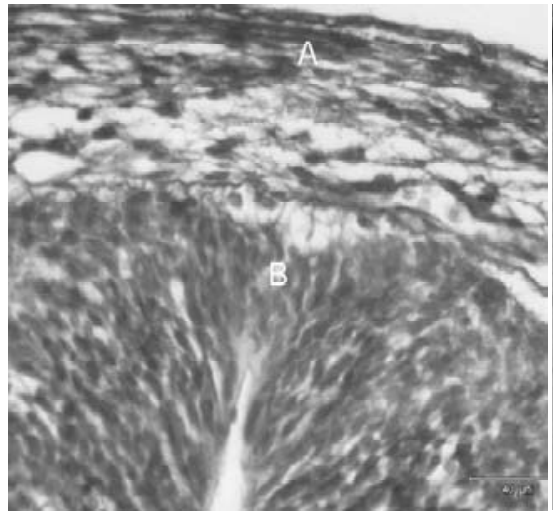

Figure 4. BMP-4 expression in a) non-neural ectoderm $b$ ) roof plate c) neural crest cells in developing spinal cord (Carnegie stage 14).

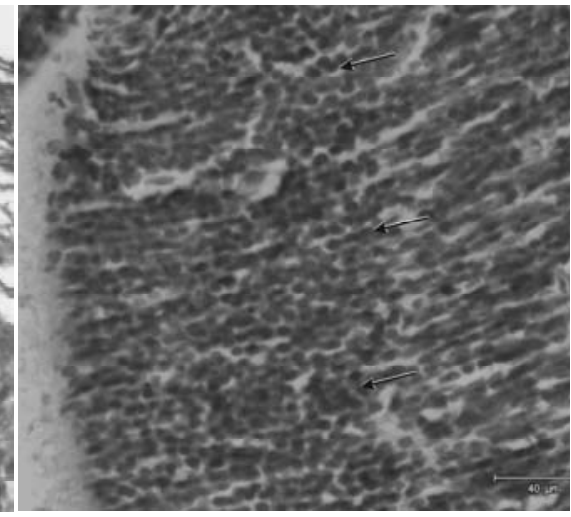

Figure 5. BMP-2 expression in the roof plate of developing spinal cord (Carnegie stage 16).

\section{CONCLUDING REMARKS}

In embryonic development BMP-s, specially BMP-2 and BMP-4, are critical signalling molecules required for the early differentiation of the embryo and establishing the dorsoventral axis. The specification of 
neuronal subtypes becomes evident with the appearance of distinct cell types at defined positions along the dorsoventral axis of the neural tube [19]. The dorsoventral patterning of the neural tube is dictated by sonic hedgehog $(\mathrm{SHH})$ emanating from ventral regions of the neural tube and BMP-s and Wnt-s originating from dorsal portions [3]. BMP and $\mathrm{SHH}$ signals appear to have opponent and antagonistic functions in the control of cell fate along the dorsoventral axis of the neural tube [12]. Together the data support the hypothesis that polypeptide growth factors of the TGF play key roles in the development of the neural tube at the initial stages of neurogenesis [20]. In addition, the members of the TGF family have specific roles in the control of proliferation and patterning of neural progenitors [38].

\section{REFERENCES}

1. Barth K.A., Kihimoto Y., Rohr K.B., Seydler C., Wilson S.W. (1999) Bmp activity establishes a gradient of positional information throughout the entire neural plate. Development, 126, 4977-4987.

2. Bier E. (1997) Anti-neural inhibition: A conserved mechanism for neural induction. Cell. 89, 5, 681-684.

3. Briscoe J., Ericson J. (2001) Specification of neuronal fates in the ventral neural tube. Development, 11, 43-49.

4. Chapman S.C., Schubert F. R., Schoenwolf G.C., Lumsden A. (2002) Analysis of spatial and temporal gene expression patterns in blastula and gastrula stage chick embryos. Dev Biol, 245, 187-199.

5. Chen D., Zhao M., Mundy G.R. (2004) Bone morphogenetic proteins. Growth factors, 22, 4, 233-241.

6. Chesnutt C., Burrus L.W., Brown M.C., Niswander L. (2004) Coordinate regulation of neural tube patterning and proliferation by TGF $\beta$ and WNT activity. Dev Biol, 274, 2, 334-337.

7. Chizhikov V.V., Millen K.J. (2004) Mechanism of roof plate formation in vertebrate CNS. Nat Rev Neurosci, 5, 10, 808-812.

8. Chizhikov V.V., Millen K.J. (2005) Roof plate-dependent patterning of the vertebrate dorsal central nervous system. Dev Biol, 277, 287-295.

9. Colas J.F., Schoenwolf G.C. (2001) Towards a cellular and molecular understanding of neurulation. Developmental Dynamics, 221, 117-145.

10. Copp A.J., Greene N.D.E. (2003) The genetic basis of mammalian neurulation. Nat Rev Genet, 4, 784-793. 
11. Dale L. Wardle F.C. (1999) A gradient of BMP activity specifies dorsal-ventral fates in early Xenopus embryos. Semin Cell Dev Biol, $10,3,319-326$.

12. Dessaud E., McMahon A.P., Briscoe J. (2008) Pattern formation in the vertebrate neural tube: a sonic hedgehog morphogen-regulated transcriptional network. Development, 135, 2489-2503.

13. Faure S., de Santa Barbara P., Roberts D.J., Whitman M. (2002) Endogenous patterns of BMP signalling during early chick development. Dev Biol, 244, 1, 44-65.

14. Furuta Y., Piston D.W., Hogan B.L.M. (1997) Bone morphogenetic proteins (BMPs) as regulators of dorsal forebrain development. Development, 124, 2203-2212.

15. Greene N.D.E. Copp A.J. (2009) Development of the vertebrate central nervous system: formation of the neral tube. Prenat Diagn, 29, 303-311.

16. Hemmati-Brivanlou A., Melton D. (1997) Vertebrate embryonic cells will become nerve cells unless told otherwise. Cell, 88, 13-17.

17. Huang X., Saint-Jeannet J.P. (2004) Induction of the neural crest and the opportunities of life on the edge. Dev Biol, 275, 1, 1-11.

18. Ille F. Atanasoski S., Falk S., Ittner L.M., Märki D., Sommer L. (2007) Wnt/BMP signal integration regulates the balance between proliferation and differentiation of neuroepithelial cells in the dorsal spinal cord. Dev Biol, 304, 1, 394-408.

19. Jessell T.M. (2000) Neuronal specification in the spinal cord: inductive signals and transcriptional codes. Genetics, 1, 20-29.

20. Jones C.M., Lyons K.M., Hogan B.L.M. (1991) Involvement of bone morphogenetic protein-4 (BMP4) and Vgr-1 in morphogenesis and neurogenesis in the mouse. Development, 111, 531-542.

21. Jones C.M., Smith J.C. (1998) Establishment of a BMP-4 morphogen gradient by long-range inhibition. Dev Biol, 194, 1, 12-17.

22. Khokha M.K., Yeh J., Grammer T.C., Harland R.M. (2005) Depletion of three BMP antagonists from Spemann's organizer leads to a catastrophic loss of dorsal structures. Dev Cell, 8, 3, 401-411.

23. Kondo M. (2007) Bone morphogenetic proteins in the early development of zebrafish. FEBS Journal, 274, 2960-2967.

24. Lee K.J., Jessell T.M. (1999) The specification of dorsal cell fates in the vertebrate central nervous system. Annnu Rev Neurosci, 22, 261-294.

25. Lee K.J., Mendelsohn M., Jesell T.M. (1998) Neuronal patterning by BMP-s: a requirement for GDF7 in the generation of a discrete class of commissural interneurons in the mouse spinal cord. Genes \& Development. 12, 3394-3407. 
26. Liu A., Niswander L.A. (2005) Bone morphogenetic protein signaling and vertebrate nervous system development. Neuroscience, 6, 945-954.

27. Lupo G., Harris W.A., Lewis K.E. (2006) Mechanisms of ventral patterning in the vertebrate nervous system. Neuroscience, 7, 103-114.

28. Matthews S.J.E. (2005) Biological activity of bone morhogenetic proteins (BMP-s). Int J Care Injured, 365, 534-537.

29. Patthey C., Gunhaga L., Edlund T. (2008) Early development of the central and peripheral nervous systems is coordinated by Wnt and BMP signals. PLoS ONE, 3e, 1625.

30. Sadler T.W. (2005) Embryology of neural tube development. Semin. Med. Genetic, 135C, 2-8.

31. Sadler T.W. (2010) Langman's medical embryology. 11-th ed. Lippincott Williams \&Wilkins.

32. Stern C.D. (2007) Neural induction: old problem, new findings, yet more questions. Development, 132, 2007-2021.

33. Stickney H.L., Imai Y., Draper B., Moens C., Talbot W.S. (2007) Zebrafish bmp4 functions during late gastrulation to specify ventroposterior cell fates. Dev Biol, 310, 1, 71-84.

34. Thawani J.P. (2010) Bone morphogenetic proteins and cancer: Review of the literature. Neurosurgery, 66, 233-246.

35. Thiery J.P. (2003) Epithelial-mesenchymal transitions in development and pathologies. Curr. Opin. Cell. Biol, 15, 6, 740-746.

36. Timmer J.R., Wang C., Niswander L. (2002) BMP signaling patterns the dorsal and intermediate neural tube via regulation of homeobox and helix-loop-helix transcription factors. Development. 129, 2459-2472.

37. Tucker J.A., Mintzer K.A., Mullins M.C. (2008) The BMP signaling gradient patterns dorso-ventral tissues in a temporally progressive manner along the anteroposterior axis. Dev Cell, 14, 1, 108-119.

38. Ulloa F., Briscoe J. (2007) Morphogens and the control of cell proliferation and patterning in the spinal cord. Cell Cycle, 6, 26402649.

39. Urist M. (1965) Bone formation by autoinduction. Science, 12, 150, 893-899.

40. Wilson L., Maden M. (2005) The mechanisms of dorsoventral patterning in the vertebrate neural tube. Dev Biol, 282, 1, 1-13.

41. Wine-Lee L., Ahn K.J., Richardson R.D., Mishina Y., Lyons K.M. (2004) Signalling through BMP type 1 receptors is required for development of interneuron cell types in the dorsal spinal cord. Development, 131, 5393-5403. 
Address for correspondence:

Marina Aunapuu

University of Tartu

Department of Anatomy

Ravila 19, Biomedicum, 50411 Tartu, Estonia

E-mail: marina.aunapuu@ut.ee 